\title{
A Wide-Band Single-Layer Patch Antenna
}

\author{
Naftali Herscovici, Senior Member, IEEE
}

\begin{abstract}
The typical single-layer patch printed on a dielectric substrate is a narrow-band element. This well-known fact is mainly due to the limitations imposed by the dielectric substrate. From efficiency and cost considerations, in most of the cases, the substrate cannot be too thick. In order to increase the microstrip element bandwidth, additional resonators in different configurations and combinations can be used: parasitic elements, slots, etc. However, the microstrip antenna element with the widest bandwidth (a variation of the aperture-fed stacked-patch element) is about $\mathbf{4 0 - 5 0 \%}$. This antenna, an aperture-fed stacked patch, has a relatively poor front-to-back ratio, due to the fact that it has a slot in the ground plane. In this paper, a new type of patch element is presented. The patch is suspended over the ground plane and supported by a nonconductive pin. It is fed by a three-dimensional (3-D) transition connecting the patch to a perpendicular connector. The typical bandwidth of this element (in terms of VSWR) is $90 \%$. When built on a large ground plane, the front-to-back of this element is better than $25 \mathrm{~dB}$ across the band.
\end{abstract}

Index Terms-Microstrip antennas.

\section{INTRODUCTION}

$\mathbf{T}$ THE suspended patch element and arrays using threedimensional (3-D) microstrip transitions were first presented in [1]. The new degree of freedom introduced by the 3-D transition clears the way for new configurations of microstrip antennas and arrays. The microstrip element proposed in this paper combines the wide-band characteristics of the element described in [2] with the options described in [3]. The element can be very high above the ground plane (so that the electrical volume can be significantly increased) and be matched using the 3-D transition (avoiding the long probe or extremely wide coplanar feeding microstrip line). The butterfly patches of [2], as well as the dipole array of [4], are elements that have a wider band than the traditional rectangular patch element. This is because they combine a number of resonators (rather than one only), which resonate at close frequencies generating the wide-band effect. Combined with the electrically large element, these geometries can generate a significant increase in the bandwidth. A number of different designs were made (some of them reported in [5]) and, in terms of VSWR, the widest band obtained was $95 \%$.

\section{DESIGN}

The wide-band microstrip single-layer patch antenna is shown in Fig. 1. The patch (Fig. 2) is $53.1 \mathrm{~mm}$ wide, 49.10 $\mathrm{mm}$ long, and suspended at $18.4 \mathrm{~mm}$ over the ground plane.

Manuscript received June 2, 1997; revised November 6, 1997.

The author is with Cushcraft Corporation, Manchester, NH 03108 USA.

Publisher Item Identifier S 0018-926X(98)02674-X.

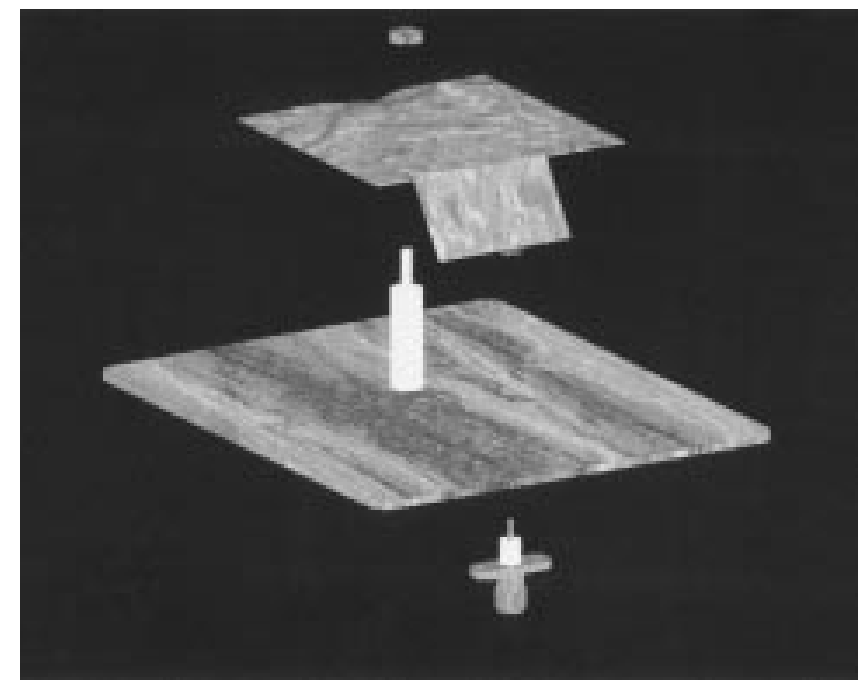

Fig. 1. The wide-band microstrip single-layer patch antenna.

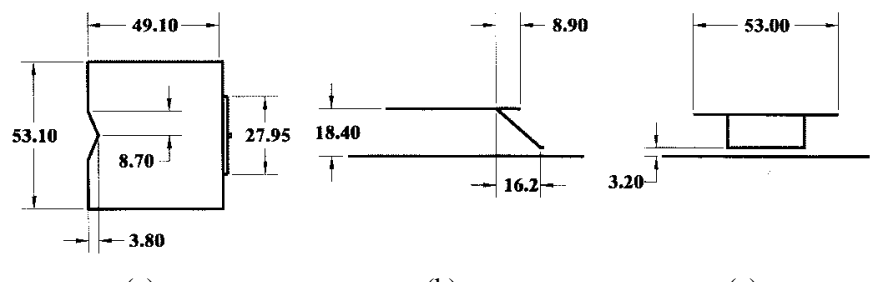

(a)

(b)

(c)

Fig. 2. The dimensions (millimeters) for the proposed wide-band microstrip single-layer patch antenna.

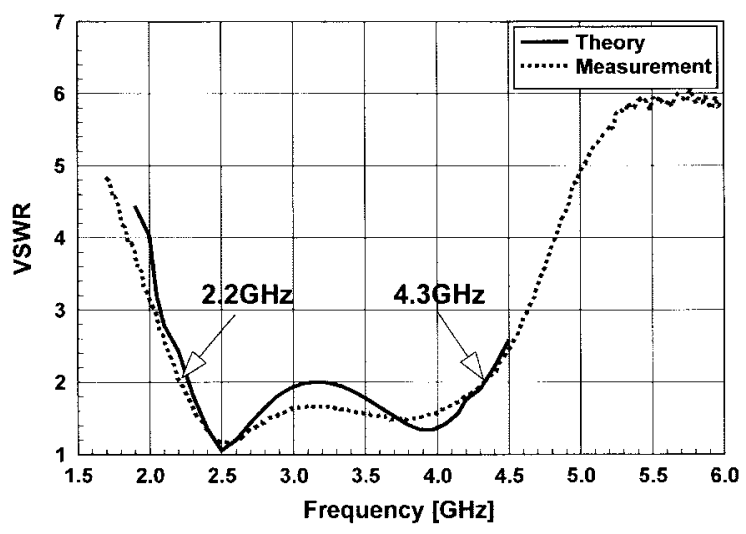

Fig. 3. The VSWR of the wide-band microstrip single-layer patch antenna.

The feeding strip is $27.95 \mathrm{~mm}$ wide, $19.30 \mathrm{~mm}$ long, and is connected to the patch at $8.90 \mathrm{~mm}$ away from the straight 


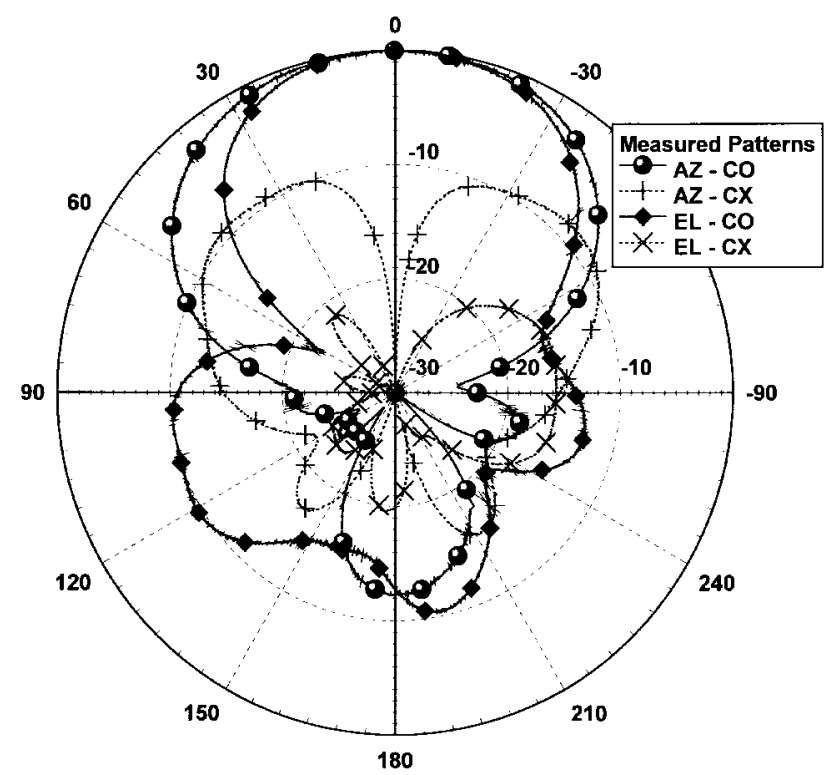

(a)

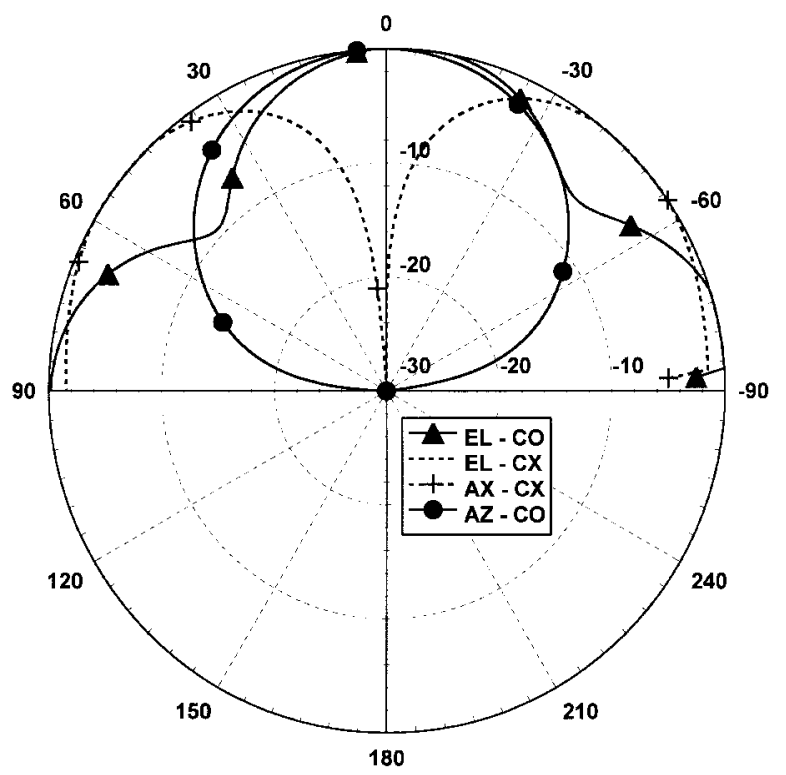

(c)

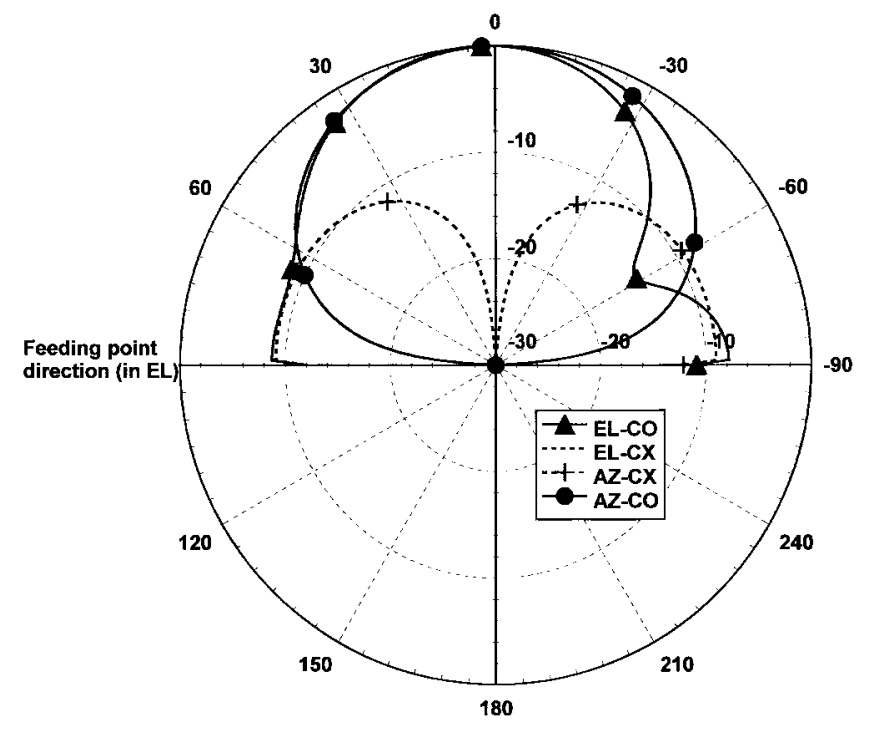

(b)

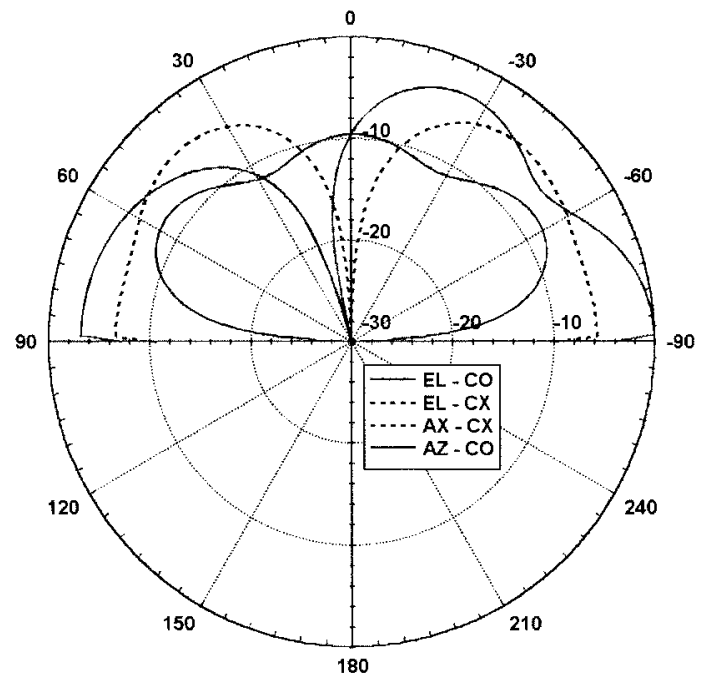

(d)

Fig. 4. The radiation patterns of the wide-band microstrip single-layer patch antenna. (a) The measured patterns at $2.54 \mathrm{GHz}$ (ground plane $=102 \mathrm{~mm} \times$ $76.2 \mathrm{~mm}$ ). (b) The calculated patterns (infinite ground plane) at $2.54 \mathrm{GHz}$ (EL-CX $<-30 \mathrm{~dB}$ ). (c) The calculated patterns (infinite ground plane) at 3.50 $\mathrm{GHz}(\mathrm{EL}-\mathrm{CX}<-30 \mathrm{~dB})$. (d) The calculated patterns (infinite ground plane) at $4.70 \mathrm{GHz}(\mathrm{EL}-\mathrm{CX}<-30 \mathrm{~dB})$.

$E$-plane edge. The angle the feeding strip makes with the patch is $55^{\circ}$ (and the connection between the strip and the input connector is $3.18 \mathrm{~mm}$ wide $)$. A plastic pin $(6.35 \mathrm{~mm}$ in diameter) supports the patch.

The design was also analyzed using Zeland Software's IE3D simulation package. The comparison between the measurements and software predictions are very close, even though (for limited memory reasons) the discretization of the device analyzed was quite rough $(0.1 \lambda)$. The VSWR of the antenna (computed and measured) is shown in Fig. 3. The difference between the two graphs is also due to the fact that the proposed antenna was built on a very small ground plane $(102 \mathrm{~mm} \times$
$76.2 \mathrm{~mm}$ ), while the computations assume an infinite ground plane.

\section{MEASUREMENTS AND DISCUSSION}

The radiation patterns of the wide-band patch are shown in Fig. 4. Fig. 4(a) shows the measured patterns at $2.54 \mathrm{GHz}$ (on a $102 \mathrm{~mm} \times 76.2 \mathrm{~mm}$ ground plane) and Fig. 4(b) shows the computed patterns at the same frequency. Here, the impact of the small ground plane is more pronounced: the crosspolarization level in the azimuth cut is higher at angles closer to broadside and in the elevation cut the cross polarization 

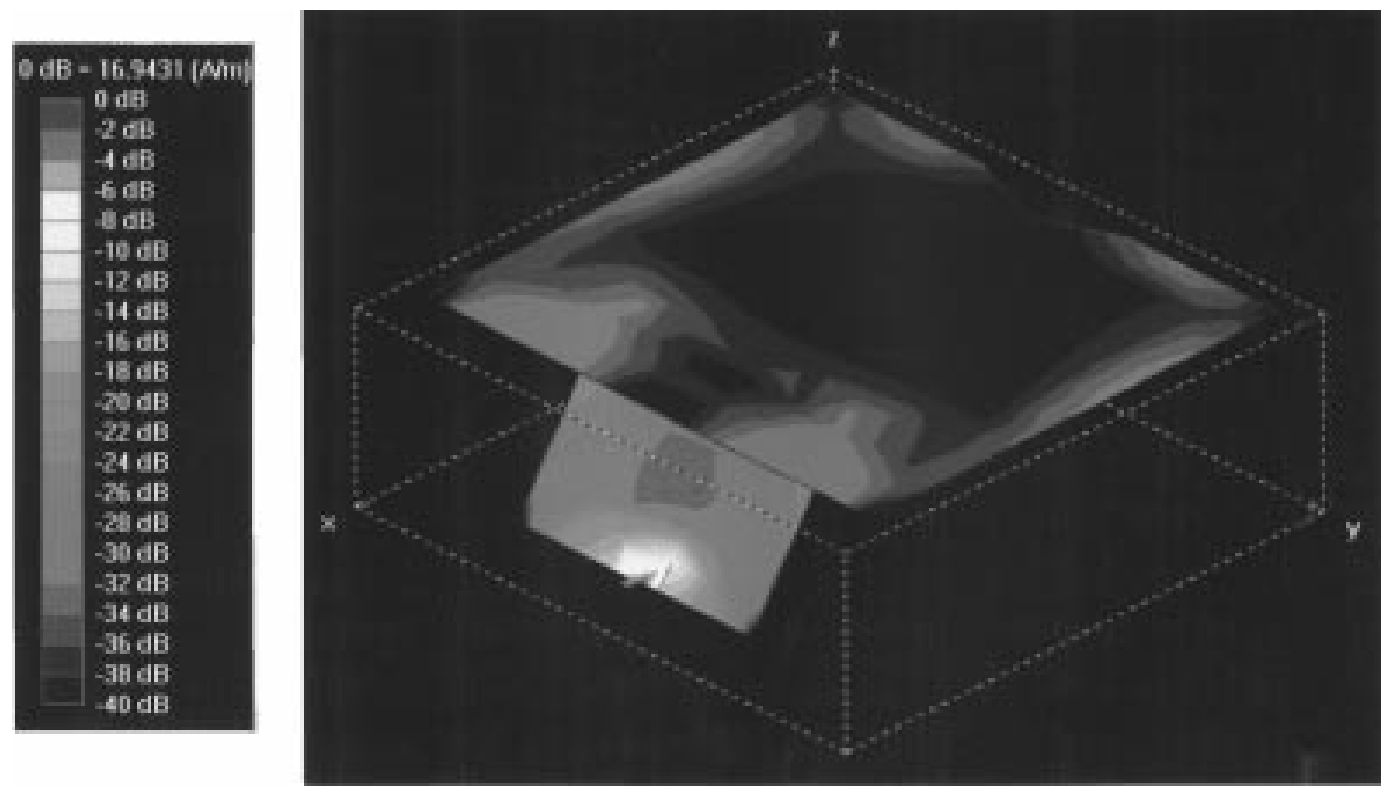

Fig. 5. The current distribution on the antenna at $4.7 \mathrm{GHz}$ (computed using IE3D).

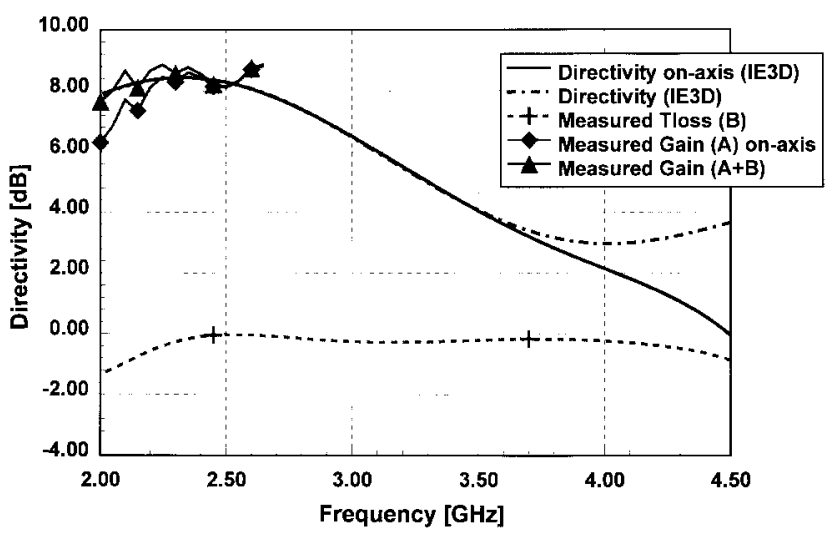

Fig. 6. The directivity and gain of the antenna versus frequency (the transmission loss is due to the mismatch only).

is considerably higher. In the elevation cut, some radiation from the feeding microstrip tab is noticed. As the frequency increases, this radiation is more significant as is shown in Fig. 4(c) and (d). At $4.7 \mathrm{GHz}$, the pattern in elevation is shown to break into two lobes due to the excitation of higher modes. In addition to that (as shown in Fig. 5), the radiation from the 3-D transition is dominating and interferes with the radiation from the patch.

Depending on the application, the bandwidth of an antenna can be defined in many ways: in terms of VSWR (as we see in Fig. 1), for less than $2: 1$, the bandwidth is about $90 \%$; in terms of directivity on axis (defined as the drop in gain of only $1.0 \mathrm{~dB}$ ), the theoretical bandwidth is about $40 \%$. The measured gain bandwidth is also 40\%. As shown in Fig. 6, the theoretical directivity bandwidth is offset somewhat with respect to the VSWR bandwidth and the overlapping between the two bands (according to the band definitions above) is about $30 \%$. The measured gain, though, shows no offset in frequency with respect to the VSWR and, thus, considering all the properties of the antenna, it can be said that the bandwidth of the wide-patch single-patch element presented in this paper is about $40 \%$.

The wide-band effect is the result of a number of factors:

1) the use of air as "dielectric substrate";

2) the large height of the element $(0.14 \lambda$ at the lower end and $0.27 \lambda$ at the higher end);

3) the use of the 3-D transition;

4) the height is such that toward the higher end of the frequency band, the ground plane is located at $0.25 \lambda$ away from the patch and simply acts as a reflector; this effect, by itself is wide-band.

\section{CONCLUSIONS}

The wide-band single-patch antenna proposed in this paper demonstrates the new possibilities introduced by the suspended microstrip technology in conjunction with the 3-D transitions of [1]. For many applications, this geometry eliminates the need for the parasitic elements and the dielectric substrate necessary to support them.

\section{ACKNOWLEDGMENT}

The author would like to thank D. Harris for helping with the measurements and S. Johnson for the 3-D pictures.

\section{REFERENCES}

[1] N. Herscovici, "A new type of microstrip arrays fed by a purely TEM feeding network," in IEEE AP-S Int. Symp., Baltimore, MD, July 1996, pp. 1318-1321.

[2] R. Zetner, J. Bartolic, and E. Zetner, "Electromagnetically coupled butterfly patch antenna," J. Int. de Nice sur les Antennes, Nice, Nov. 1996, pp. 588-591.

[3] N. Herscovici, "Suspended three-dimensional microstrip radiators," U.S patent application 08/669,047, Apr. 1995.

[4] F. Croq and D. M. Pozar, "Multifrequency operation of microstrip antennas using aperture coupled parallel resonators," IEEE Trans. Antennas Propagat., vol. 40, pp. 1367-1375, Nov. 1992.

[5] N. Herscovici, "New types of microstrip antenna for UHF," Microwave J., vol. 40, no 5, pp. 312-316, May 1971. 


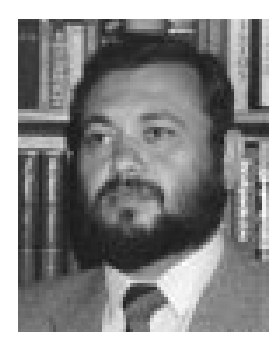

Naftali Herscovici (S'80-M'92-SM'94) was born in Bucharest, Romania, in 1954. He received the B.Sc., M.Sc., and Ph.D. degrees in electrical engineering from the Technion, Haifa, Israel, and the University of Massachusetts, Amherst, in 1978, 1985 , and 1992, respectively.

Between 1983 and 1989, he was employed by Rafael, Haifa, Israel as an Antenna Engineer. There he was engaged in the research and development of microwave antennas. He is currently with Cushcraft Corp., Manchester, NH. His research interests include microstrip arrays, reflector antennas and feeds, pattern synthesis, and antenna modeling.

Dr. Herscovici is currently the Chairman of the IEEE Antenna and Propagation Society, Boston Chapter. 